\title{
FURTHER STUDIES ON RENAL TUBULAR CONSERVATION OF FREE AMINO ACIDS IN EARLY INFANCY
}

\author{
BY \\ DONOUGH O'BRIEN and L. JOSEPH BUTTERFIELD \\ From the Department of Pediatrics, University of Colorado Medical Center, Denver 20, Colorado, U.S.A.
}

(RECEIVED FOR PUBLICATION APRIL 25, 1963)

The higher rates of excretion in the urine of the premature infant of both total free alpha amino nitrogen and of individual amino acids as compared to the full-term infant, the older child, and the adult have been repeatedly documented (Childs, 1952; Dustin, Moore and Bigwood, 1955; Fowler, Norton, Cheung and Pratt, 1957; Jagenburg, 1959; O'Brien, Bergstedt, Butterfield, Ibbott and Lubchenco, 1960; Sereni, McNamara, Shibuya, Kretchmer and Barnett, 1955; Woolf and Norman, 1957). In only one study, however, has there been an attempt to extend these observations to the measurement of the renal clearances of single amino acids. Using the semi-quantitative technique of paper chromatography, Sereni et al. (1955) demonstrated in the case of 13 individual amino acids that this aminoaciduria in the premature infant was due to diminished renal tubular reabsorption and that it was also limited by the small glomerular filtration rate in the first month of life. Additional and more precise data obtained by column chromatography in both normal adults and adults and children with a variety of metabolic defects has been reviewed in detail (Scriver, 1962).

The purpose of this study was to obtain comparable information for the premature and full-term infant at the time of maximal aminoaciduria and so to extend the earlier observations based on paper chromatography as well as to provide a more accurate baseline for the appraisal of aminoacidurias in this age-group.

\section{Clinical Material and Methods}

Four healthy premature male infants and three fullterm male infants (Table 1) were studied at an age between 30 and 60 days when previous observations (O'Brien et al., 1960; Sereni et al., 1955) had shown that the aminoaciduria would be most pronounced. The subjects were maintained for four days before the collection period on $120-150 \mathrm{ml} . / \mathrm{kg} . / 24$ hours of a conventional partially skimmed milk and carbohydrate mixture containing 67 calories and $2.7 \mathrm{~g}$. protein per $100 \mathrm{ml}$. They were placed on a metabolic frame (Hepner and Lubchenco, 1960) from which all urine could be collected into a time flow fraction collector. After a fast of not less than four hours, the time of the next voiding was noted. The infant was then given $25 \mathrm{ml} / \mathrm{kg}$. of $5 \%$ dextrose in water and all urine was subsequently collected for a timed period which ranged from 97-174 minutes; samples were frozen pending the estimation of amino acids. Similar studies were carried out on three fasting healthy male adults.

A scalp vein sample of approximately $5 \mathrm{ml}$. was taken for the assay of creatinine and free amino acids at the end of the collection period rather than in the middle because of evidence that such procedures might signi-

TABLE 1

COLLECTION DATA AND CREATININE CLEARANCES

\begin{tabular}{|c|c|c|c|c|c|c|c|c|c|c|c|c|c|c|}
\hline & & & & & Prem. 1 & Prem. 2 & Prem. 3 & Prem. 4 & $\underset{\text { term } 1}{\text { Full- }}$ & $\underset{\text { term } 2}{\text { Full- }}$ & $\underset{\text { term } 3}{\text { Full- }}$ & Adult 1 & Adult 2 & Adult 3 \\
\hline $\begin{array}{l}\text { Age (days) } \\
\text { Birth weight (g.) } \\
\text { Current weight (g.) } \\
\text { Length (cm.) } \\
\text { Surface area (m.2) } \\
\text { Collection time (min.) } \\
\text { Urine volume (ml.) } \\
\text { Plasma creatinine (mg. } \\
\text { Urine creatinine (mg./ } \\
\text { Creatinine clearances (C) } \\
\text { (ml./min./1.73 }\end{array}$ & $\begin{array}{l}\ldots \\
\cdots \\
\cdots \\
\cdots \\
\cdots \\
\cdots \\
.100 \mathrm{n} \\
100 \mathrm{ml} \\
\text { Cer) } \\
\text { m.2) }\end{array}$ & $\begin{array}{l}\ldots \\
\ldots \\
\ldots \\
\ldots \\
\ldots \\
\text { i.) } \\
.) \\
\ldots\end{array}$ & $\begin{array}{l}\cdots \\
\cdots \\
\cdots \\
\cdots \\
\cdots \\
\cdots \\
\cdots\end{array}$ & $\begin{array}{l}\cdots \\
\cdots \\
. \\
\cdots \\
\cdots \\
\cdots \\
\cdots \\
. .\end{array}$ & $\begin{array}{c}36 \\
1,230 \\
2,100 \\
44 \\
0 \cdot 153 \\
174 \\
31 \cdot 0 \\
0 \cdot 45 \\
7 \cdot 5 \\
33 \cdot 6\end{array}$ & $\begin{array}{c}50 \\
980 \\
1,920 \\
42 \cdot 5 \\
0 \cdot 144 \\
108 \\
26 \cdot 0 \\
0 \cdot 56 \\
5 \cdot 4\end{array}$ & $\begin{array}{c}57 \\
1,225 \\
1,970 \\
49 \\
0 \cdot 158 \\
109 \\
21 \cdot 0 \\
0 \cdot 88 \\
13 \cdot 6\end{array}$ & $\begin{array}{c}53 \\
1,250 \\
1,930 \\
44 \\
0 \cdot 147 \\
107 \\
28 \cdot 0 \\
0 \cdot 66 \\
8 \cdot 5\end{array}$ & $\begin{array}{c}31 \\
3,520 \\
3,990 \\
57 \cdot 5 \\
0 \cdot 24 \\
97 \\
41 \\
0 \cdot 55 \\
14 \cdot 6\end{array}$ & $\begin{array}{c}39 \\
3,030 \\
3,720 \\
53 \\
0 \cdot 22 \\
132 \\
74 \\
0 \cdot 56 \\
6 \cdot 3\end{array}$ & $\begin{array}{c}46 \\
2,551 \\
3,120 \\
53 \\
0 \cdot 205 \\
163 \\
74 \\
0 \cdot 58 \\
9 \cdot 1\end{array}$ & $\begin{array}{c}37 \text { yrs. } \\
8 \overline{k g} . \\
184 \\
2 \cdot 1 \\
207 \\
217 \\
1 \cdot 20 \\
137\end{array}$ & $\begin{array}{c}34 \mathrm{yrs} . \\
70 \mathrm{~kg} \\
180 \\
1 \cdot 75 \\
120 \\
70 \\
1 \cdot 11 \\
209\end{array}$ & $\begin{array}{c}35 \text { yrs. } \\
79 \cdot 5 \mathrm{~kg} . \\
183 \\
1.9 \\
122 \\
374 \\
1.04 \\
44 \cdot 3\end{array}$ \\
\hline
\end{tabular}


AMINO ACID CONCENTRATIONS IN PLASMA (ßa)

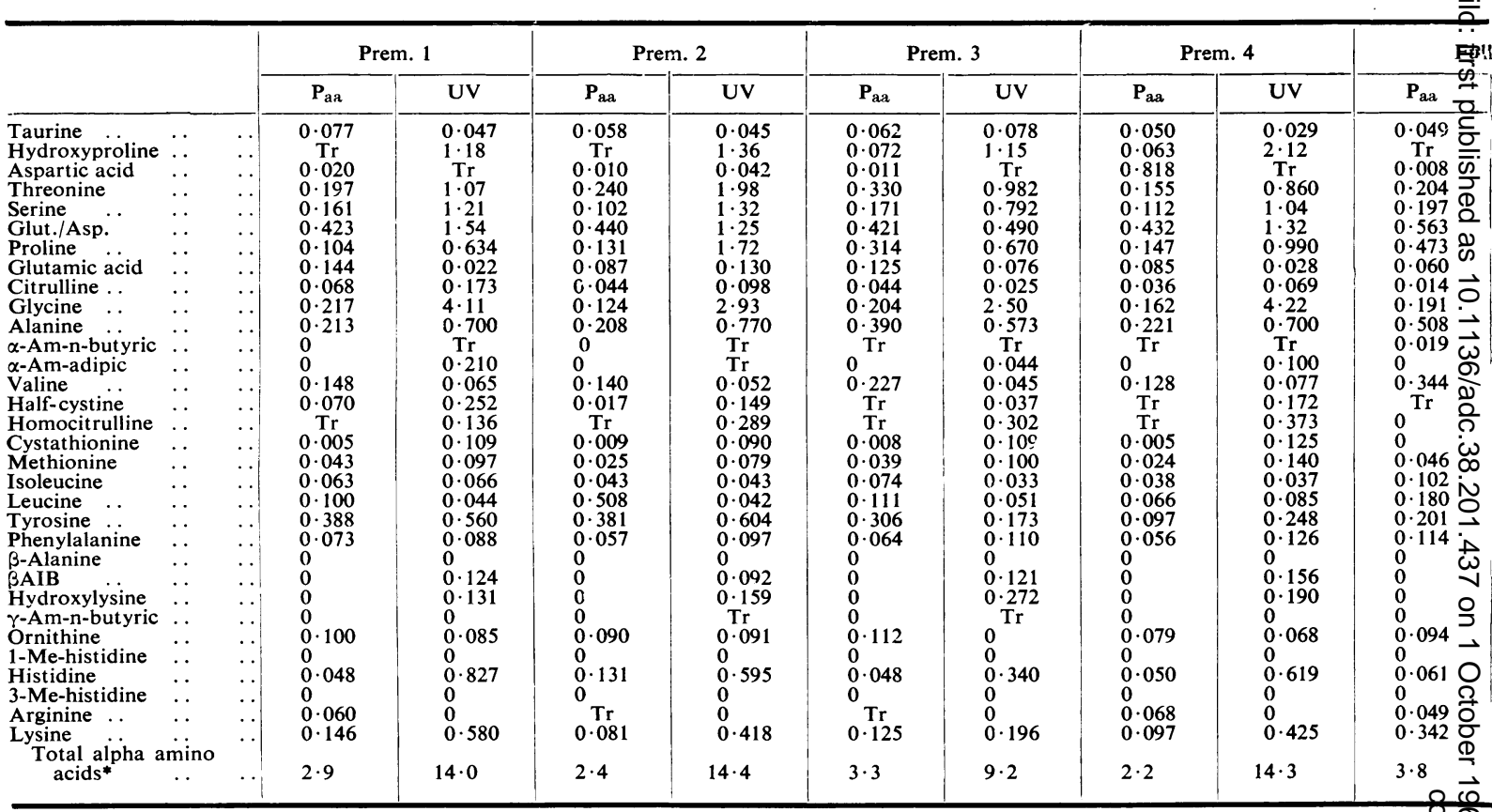

$\mathbf{P}_{\mathrm{ad}}=$ Plasma free amino acid concentration in $\mu \mathrm{mol} . / \mathrm{ml}$.

$\operatorname{Tr}=$ Detectable but insufficient to measure accurately

* Derived from sum of measured amino acids.

ficantly alter glomerular filtration rate (McCance, Naylor and Widdowson, 1954). Creatinine in plasma and urine was measured specifically in triplicate within two hours of sample collection by the Jaffe reaction after adsorption on to and elution from Lloyd's reagent (Owen, Iggo, Scandrett and Stewart, 1954). The remainder of the plasma was at once deproteinized (Stein and Moore, 1954) and assayed for amino acids on sulphonated polystyrene resin columns (Spackman, Stein and Moore, 1958) using a Beckman/Spinco amino acid analyser. Urine samples were similarly assayed after acidifying to $p \mathrm{H} \mathbf{2 \cdot 0}$. Glutamine and asparagine are eluted simultaneously from the column and are expressed in terms of glutamine; these values must be treated with reserve because of the variable destruction of glutamine during deproteinization. Tryptophane is not recovered quantitatively from such a column (Stein and Moore, 1954), and in none of the runs on urine or plasma was there a measurable peak in the tryptophane position. Reproducibility for individual plasma amino acids for all stages of this assay as expressed by the coefficient of variation was $\pm 5 \cdot 7 \%(2 \cdot 6-7 \cdot 6 \%)$ except for half-cystine and histidine which gave values of $\pm 10 \%$. However, as Jagenburg (1959) has pointed out, there are technical reasons for supposing that cystathionine, methionine, leucine and isoleucine in urine are overestimated; but the error is not sufficient to affect the general conclusions on tubular reabsorption of these amino acids.

\section{Results and Discussion}

Values for creatinine concentration in plasma and urine and for endogenous creatinine clearance rates are given in Table 1. Plasma amino acid concentrations $\left(\mathbf{P}_{\mathrm{aa}}\right)$ and urinary amino acid excretion rates (UV) are shown in Table 2, and amino acid clearances $\left(\mathrm{C}_{\mathrm{aa}}\right)$ and percentage tubular reabsorption (TR) in Table 3. In calculating TR, the endogenous creatinine clearance has been accepted as the measure of glomerular filtration rate (Barnett and Vesterdal, 1953).

Two major factors must be considered in any evaluation of the higher urinary losses of amino acids in infants as compared to older children and adults. The first of these is the size of the filtered load presented to the proximal tubule. Doolan, Harper, Hutchin and Shreeve (1955) and Doolan, Harper, Hutchin and Alpen (1956) have shown, for example, that in adults the intravenous loading of a mixture of amino acids produces a striking reduction in the tubular conservation of threonine, serine, 


\begin{tabular}{|c|c|c|c|c|c|c|c|c|c|c|}
\hline \multirow{2}{*}{$\frac{\text { Tierm } 1}{U V}$} & \multicolumn{2}{|c|}{ Full Term 2} & \multicolumn{2}{|c|}{ Full Term 3} & \multicolumn{2}{|c|}{ Adult 1} & \multicolumn{2}{|c|}{ Adult 2} & \multicolumn{2}{|c|}{ Adult 3} \\
\hline & $\mathbf{P}_{\mathbf{a a}}$ & UV & $\mathbf{P}_{\mathrm{aa}}$ & UV & $\mathbf{P}_{\mathrm{aa}}$ & UV & $\mathbf{P}_{\mathbf{a a}}$ & UV & $\mathbf{P}_{\mathbf{a a}}$ & UV \\
\hline $\begin{array}{l}0 \cdot 183 \\
2 \cdot 58 \\
\text { Tr } \\
1 \cdot 32 \\
2 \cdot 32 \\
2 \cdot 00 \\
5 \cdot 40 \\
0 \cdot 041 \\
0 \cdot 040 \\
8 \cdot 40 \\
2 \cdot 12 \\
0 \\
0 \cdot 230 \\
0 \cdot 120 \\
0 \cdot 260 \\
0 \cdot 240 \\
0 \cdot 170 \\
0 \cdot 127 \\
0 \cdot 102 \\
0 \cdot 154 \\
0 \cdot 380 \\
0 \cdot 118 \\
0 \\
0 \cdot 250 \\
0 \cdot 110 \\
\text { Tr } \\
0 \cdot 082 \\
5 \cdot 029 \\
1 \cdot 80 \\
0 \cdot 065 \\
0 \cdot 045 \\
1 \cdot 37\end{array}$ & $\begin{array}{l}0 \cdot 103 \\
\operatorname{Tr} \\
0 \cdot 017 \\
0 \cdot 178 \\
0 \cdot 165 \\
0 \cdot 365 \\
0 \cdot 413 \\
0 \cdot 204 \\
\operatorname{Tr} \\
0 \cdot 180 \\
0 \cdot 496 \\
\quad \operatorname{Tr} \\
0 \\
0 \cdot 333 \\
\operatorname{Tr} \\
0 \\
\operatorname{Tr} \\
0 \cdot 033 \\
0 \cdot 080 \\
0 \cdot 143 \\
0 \cdot 119 \\
0 \cdot 065 \\
0 \\
0 \\
0 \\
0 \\
0 \cdot 077 \\
0 \\
0 \cdot 052 \\
0 \\
0 \cdot 096 \\
0 \cdot 215\end{array}$ & $\begin{array}{l}0 \cdot 013 \\
0 \cdot 705 \\
0 \cdot 160 \\
0 \cdot 675 \\
1 \cdot 09 \\
1 \cdot 15 \\
1 \cdot 11 \\
0 \cdot 622 \\
\text { Tr } \\
3 \cdot 76 \\
1 \cdot 21 \\
0 \\
0 \cdot 176 \\
0 \cdot 165 \\
0 \cdot 343 \\
0 \cdot 233 \\
0 \cdot 119 \\
0 \cdot 141 \\
0 \cdot 137 \\
0 \cdot 172 \\
0 \cdot 224 \\
0 \cdot 123 \\
0 \\
0 \cdot 176 \\
0 \cdot 110 \\
0 \\
0 \cdot 084 \\
0 \\
0 \cdot 855 \\
0 \\
0 \cdot 097 \\
1 \cdot 36\end{array}$ & 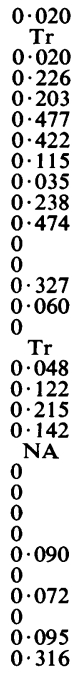 & $\begin{array}{l}0 \cdot 023 \\
0 \cdot 790 \\
0 \cdot 323 \\
1 \cdot 34 \\
1 \cdot 95 \\
1 \cdot 71 \\
0 \cdot 730 \\
0 \cdot 255 \\
\mathrm{Tr} \\
5 \cdot 28 \\
1 \cdot 36 \\
0 \\
0 \cdot 230 \\
0 \cdot 106 \\
0 \cdot 148 \\
0 \cdot 129 \\
0 \cdot 118 \\
0 \cdot 140 \\
0 \cdot 156 \\
0 \cdot 167 \\
0 \cdot 243 \\
0 \cdot 137 \\
0 \\
0 \cdot 425 \\
0 \cdot 057 \\
0 \\
0 \cdot 057 \\
0 \\
1 \cdot 49 \\
\mathrm{Tr} \\
\mathrm{T} \cdot \\
0 \cdot 724\end{array}$ & $\begin{array}{l}0 \cdot 074 \\
\operatorname{Tr} \\
0 \cdot 004 \\
0 \cdot 092 \\
0 \cdot 094 \\
0 \cdot 500 \\
0 \cdot 243 \\
0 \cdot 056 \\
0 \cdot 027 \\
0 \cdot 150 \\
0 \cdot 373 \\
0 \cdot 011 \\
0 \\
0 \cdot 182 \\
0 \cdot 055 \\
0 \\
0 \\
0 \cdot 020 \\
0 \cdot 055 \\
0 \cdot 103 \\
0 \cdot 051 \\
0 \cdot 047 \\
0 \\
0 \\
0 \\
0 \\
0 \cdot 059 \\
0 \\
0 \cdot 064 \\
0 \\
0 \cdot 038 \\
0 \cdot 169\end{array}$ & $\begin{array}{l}0 \cdot 501 \\
0 \\
0 \cdot 057 \\
0 \cdot 084 \\
0 \cdot 296 \\
0 \cdot 475 \\
0 \\
0 \cdot 016 \\
\text { Tr } \\
0 \cdot 825 \\
0 \cdot 207 \\
0 \cdot 025 \\
0 \cdot 019 \\
0 \cdot 032 \\
0 \cdot 051 \\
0 \cdot 038 \\
0 \cdot 014 \\
0 \cdot 035 \\
0 \cdot 022 \\
0 \cdot 032 \\
0 \cdot 092 \\
0 \cdot 049 \\
0 \\
0 \cdot 036 \\
0 \cdot 019 \\
\text { Tr } \\
\text { Tr } \\
0 \cdot 578 \\
0 \cdot 533 \\
0 \cdot 229 \\
0 \\
0 \cdot 209\end{array}$ & $\begin{array}{l}0 \cdot 047 \\
0 \\
0 \cdot 010 \\
0 \cdot 139 \\
0 \cdot 105 \\
0 \cdot 519 \\
0 \cdot 154 \\
0 \cdot 155 \\
0 \cdot 023 \\
0 \cdot 208 \\
0 \cdot 364 \\
0 \cdot 027 \\
0 \\
0 \cdot 248 \\
0 \cdot 076 \\
0 \\
0 \\
0 \cdot 032 \\
0 \cdot 071 \\
0 \cdot 141 \\
0 \cdot 067 \\
0 \cdot 066 \\
0 \\
0 \\
0 \\
0 \\
0 \cdot 083 \\
0 \\
0 \cdot 069 \\
0 \\
0 \cdot 057 \\
0 \cdot 178\end{array}$ & $\begin{array}{l}1 \cdot 31 \\
0 \\
0 \cdot 090 \\
0 \cdot 102 \\
0 \cdot 253 \\
0 \cdot 485 \\
0 \\
0 \cdot 014 \\
\text { Tr } \\
0 \cdot 886 \\
0 \cdot 263 \\
0 \cdot 039 \\
0 \cdot 017 \\
0 \cdot 036 \\
0 \cdot 056 \\
0 \cdot 036 \\
0 \cdot 020 \\
0 \cdot 031 \\
0 \cdot 036 \\
0 \cdot 048 \\
0 \cdot 102 \\
0 \cdot 063 \\
0 \\
0 \cdot 093 \\
\text { Tr } \\
\text { Tr } \\
\text { Tr } \\
0 \cdot 196 \\
0 \cdot 294 \\
0 \cdot 280 \\
0 \\
0 \cdot 114\end{array}$ & $\begin{array}{l}0 \cdot 052 \\
0 \\
0 \cdot 008 \\
0 \cdot 116 \\
0 \cdot 089 \\
0 \cdot 406 \\
0 \cdot 201 \\
0 \cdot 192 \\
\quad T r \\
0 \cdot 233 \\
0 \cdot 354 \\
0 \cdot 017 \\
0 \\
0 \cdot 206 \\
0 \cdot 075 \\
0 \\
0 \\
0 \cdot 012 \\
0 \cdot 065 \\
0 \cdot 121 \\
0 \cdot 043 \\
0 \cdot 045 \\
0 \\
0 \\
0 \\
0 \\
0 \cdot 072 \\
0 \\
0 \cdot 067 \\
0 \\
0 \cdot 041 \\
0 \cdot 170 \\
0\end{array}$ & $\begin{array}{l}0 \cdot 366 \\
0 \\
0 \cdot 028 \\
0 \cdot 044 \\
0 \cdot 089 \\
0 \cdot 175 \\
0 \\
0 \cdot 008 \\
0 \\
0 \cdot 414 \\
0 \cdot 087 \\
0 \cdot 014 \\
0 \\
0 \cdot 005 \\
0 \cdot 020 \\
0 \cdot 026 \\
0 \cdot 013 \\
0 \cdot 023 \\
0 \cdot 009 \\
0 \cdot 016 \\
0 \cdot 081 \\
0 \cdot 043 \\
0 \\
0 \cdot 014 \\
0 \\
\text { Tr } \\
\text { Tr } \\
0 \cdot 528 \\
0 \cdot 147 \\
0 \cdot 082 \\
0 \\
0 \cdot 022\end{array}$ \\
\hline $30 \cdot 1$ & $3 \cdot 3$ & $15 \cdot 0$ & $3 \cdot 7$ & $18 \cdot 1$ & $2 \cdot 5$ & $4 \cdot 5$ & $2 \cdot 8$ & $4 \cdot 8$ & $2 \cdot 6$ & $2 \cdot 3$ \\
\hline
\end{tabular}

$U V=$ Urinary amino acid excretion in $\mu \mathrm{mol} . / \mathrm{min} . / 1 \cdot 73 \mathrm{~m}^{2}$.

$\mathrm{NA}=$ Technically unsatisfactory chromatogram.

glycine and histidine. Webber, Brown and Pitts (1961) and Webber (1962) have also demonstrated in dogs that the infusion of any single basic, acidic or neutral amino acid will primarily increase tubular rejection of other acids in the same group. No data on the effects of increased tubular loads are available for the small infant; but the fasting serum levels of alanine, valine, leucine, isoleucine and proline are higher in the infant than in the adult. Sereni et al. (1955) showed, however, that the impact of these increased plasma levels on the tubular load was counteracted in the least mature infants by their small glomerular filtration rate.

The second factor is that of transport across the luminal membrane, in turn a function of molecular charge and stearic relations. Thus the neutral amino acids, alanine, $\alpha$-aminobutyric, valine, leucine and isoleucine are reabsorbed as effectively in the infant as in the adult despite uniformly higher plasma levels in all cases except $\alpha$-aminobutyric. It is of interest that glycine does not behave in this manner; its special position may relate not only to its being the shortest chain and therefore the least lipophilic of the neutral acids but to the other factors that affect its absorption. Histidine with its syclic side chain is also less well absorbed in the infant than the longer chain neutral acids.

The dicarboxylic acid glutamic is as well reabsorbed in the infant as in the adult although its monoamide glutamine shows some impairment in premature and full-term infants. Tubular rejection of aspartic acid on the other hand, although similar at all ages, is uniformly greater than of glutamic acid. These two acidic amino acids have been shown by Webber (1962) to inhibit each other competitively at the tubular membrane but not to interfere significantly with the reabsorption of the neutral amino acids.

The neutral aromatic acids, phenylalanine and tyrosine, are efficiently conserved at all stages of maturity. Phenylalanine has been shown by Webber (1962) to compete for reabsorption with other neutral acids, but whether it does so with tyrosine in the brain (Neame, 1961) is not known.

The basic amino acids ornithine, arginine, lysine and cystine have a known common reabsorptive pathway (Robson and Rose, 1957). Plasma levels are similar at the different ages except for the high 
RENAL CLEARANCES (Caa) AND RENAL TUBUL

\begin{tabular}{|c|c|c|c|c|c|c|c|c|c|c|c|c|}
\hline & & & \multicolumn{2}{|c|}{ Prem. 1} & \multicolumn{2}{|c|}{ Prem. 2} & \multicolumn{2}{|c|}{ Prem. 3} & \multicolumn{2}{|c|}{ Prem. 4} & \multicolumn{2}{|r|}{$\overrightarrow{\mathrm{E}}$} \\
\hline & & & $\mathrm{C}_{\mathrm{aa}}$ & TR & $\mathrm{C}_{\mathrm{aa}}$ & TR & $\mathrm{C}_{\mathrm{aa}}$ & TR & $\mathrm{C}_{\mathrm{aa}}$ & TR & $\mathrm{C}_{\mathrm{aa}}$ & $\overline{0}$ \\
\hline 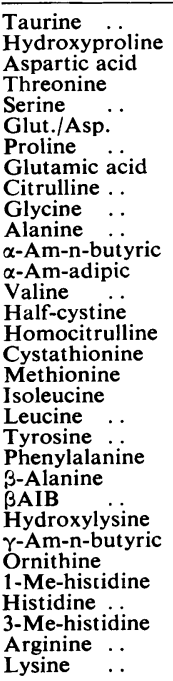 & $\begin{array}{l}\ldots \\
\ldots \\
\ldots \\
\cdots \\
\cdots \\
\cdots \\
\cdots \\
\cdots \\
\cdots \\
\cdots \\
\cdots \\
\cdots \\
\cdots \\
\cdots \\
\cdots \\
\cdots \\
\cdots \\
\cdots \\
\cdots \\
\cdots\end{array}$ & 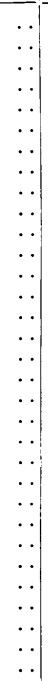 & $\begin{array}{c}0 \cdot 60 \\
- \\
5 \cdot 4 \\
7 \cdot 5 \\
3 \cdot 6 \\
6 \cdot 1 \\
0 \cdot 15 \\
2 \cdot 5 \\
19 \\
3 \cdot 3 \\
\overline{-} \\
0 \cdot 44 \\
3 \cdot 6 \\
22 \\
2 \cdot 3 \\
1 \cdot 0 \\
0 \cdot 44 \\
1 \cdot 4 \\
1 \cdot 2 \\
\overline{-} \\
\overline{-} \\
0 \cdot 85 \\
17 \\
\overline{-} \\
4 \cdot 0\end{array}$ & $\begin{array}{l}98 \\
(1) \\
(2) \\
84 \\
78 \\
89 \\
82 \\
99 \\
93 \\
44 \\
90 \\
(1) \\
(1) \\
99 \\
89 \\
(1) \\
35 \\
93 \\
97 \\
99 \\
96 \\
96 \\
(1) \\
(1) \\
97 \\
49 \\
(2) \\
88\end{array}$ & $\begin{array}{c}0 \cdot 77 \\
4 \cdot 2 \\
8 \cdot 2 \\
13 \\
2 \cdot 8 \\
13 \\
1 \cdot 5 \\
2 \cdot 2 \\
24 \\
3 \cdot 7 \\
= \\
0 \cdot 37 \\
8 \cdot 8 \\
10 \\
3 \cdot 2 \\
1 \cdot 0 \\
0 \cdot 72 \\
1 \cdot 6 \\
1 \cdot 7 \\
- \\
- \\
\overline{-} \\
1 \cdot 0 \\
19 \\
- \\
5 \cdot 2\end{array}$ & $\begin{array}{l}97 \\
(1) \\
85 \\
71 \\
54 \\
90 \\
53 \\
95 \\
92 \\
15 \\
87 \\
(1) \\
(1) \\
99 \\
68 \\
(1) \\
64 \\
88 \\
96 \\
97 \\
94 \\
94 \\
(1) \\
(1) \\
96 \\
31 \\
(2) \\
81\end{array}$ & $\begin{array}{c}1 \cdot 3 \\
16 \\
3 \cdot 0 \\
4 \cdot 6 \\
1 \cdot 2 \\
2 \cdot 1 \\
0 \cdot 61 \\
0 \cdot 57 \\
12 \\
1 \cdot 5 \\
- \\
0 \cdot 20 \\
- \\
14- \\
2 \cdot 6 \\
0 \cdot 44 \\
0.46 \\
0 \cdot 56 \\
1 \cdot 7 \\
- \\
- \\
- \\
- \\
7 \cdot 1 \\
= \\
1 \cdot 6\end{array}$ & $\begin{array}{l}96 \\
51 \\
(2) \\
91 \\
86 \\
96 \\
94 \\
98 \\
98 \\
63 \\
95 \\
(1) \\
(1) \\
99 \\
(1) \\
(1) \\
58 \\
92 \\
99 \\
99 \\
98 \\
95 \\
(1) \\
(1) \\
-(2) \\
78 \\
(2) \\
95\end{array}$ & $\begin{array}{c}0 \cdot 58 \\
34 \\
5 \cdot 5 \\
9 \cdot 3 \\
3 \cdot 1 \\
6 \cdot 7 \\
0 \cdot 33 \\
1 \cdot 9 \\
26 \\
3 \cdot 2 \\
- \\
0 \cdot 60 \\
- \\
25- \\
5 \cdot 8 \\
0 \cdot 97 \\
1 \cdot 3 \\
2 \cdot 6 \\
2 \cdot 2 \\
- \\
- \\
- \\
0 \cdot 86 \\
12- \\
- \\
4 \cdot 4\end{array}$ & $\begin{array}{l}98 \\
15 \\
(2) \\
86 \\
77 \\
92 \\
83 \\
99 \\
95 \\
34 \\
92 \\
(1) \\
(1) \\
98 \\
(1) \\
(1) \\
37 \\
85 \\
98 \\
97 \\
93 \\
94 \\
\overline{(1)} \\
(1) \\
98 \\
\overline{69} \\
(2) \\
89\end{array}$ & $\begin{array}{c}3 \cdot 8 \\
- \\
6 \cdot 5 \\
12.6 \\
3 \cdot 6 \\
14 \\
0 \cdot 68 \\
2 \cdot 9 \\
44.2 \\
4 \cdot 2 \\
= \\
0 \cdot 35 \\
- \\
- \\
2 \cdot 7 \\
1 \cdot 0 \\
0 \cdot 86 \\
1 \cdot 9 \\
1 \cdot 0 \\
- \\
- \\
- \\
0.87 \\
29- \\
0.91 \\
4 \cdot 0\end{array}$ & 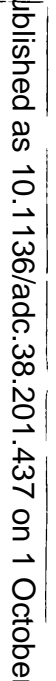 \\
\hline
\end{tabular}

(1) = O-Tr in plasma but present in significant amounts in urine.

(2) = Detectable in plasma but not in urine except in traces.

lysine in the full-term infants, and there is a variable impairment of tubular reabsorption in the infant which is most marked in the premature. This pathway appears to be quite distinct from that for the acidic amino acids, although there may be some overlap with that for the neutral acids (Webber, 1962). The pattern appears to be shared by the two other basic amino acids citrulline and hydroxylysine.

The neutral hydroxy acids are the one group affected by pre-renal factors in that the high urinary losses are linked to high plasma levels. This is also the case for methionine, a neutral but structurally unrelated amino acid.

The imino acids and glycine have also been shown by Scriver, Schafer and Efron (1961) to have properties in common during tubular reabsorption. These three amino acids show significant tubular rejection as a group in infancy, and this is particularly demonstrated in the first full-term infant. Glycine, in addition, may compete with phosphorus for reabsorption (Evered, (1956) as well as being reabsorbed less effectively after a load of neutral amino acids (Doolan et al., 1955, 1956; Webber, 1962).

The five amino acids hydroxylysine, homocitrulline, cystathionine, $\beta$-aminoisobutyric and $\alpha$-aminoadipic have in common an unusually low renal threshold at all ages. Cusworth and Dent (1960) have pointed out that substances behaving in this way are not normally transported in the extracellular water in significant amounts.

The possibility that homocitrulline might be an artefact derived from lysine and cyanate within the bladder or on storage of the urine has been suggested (Gerritsen, Lipton, Strong and Waisman, 1961; Stark, Stein and Moore, 1960). However, incubation of a sterile urine sample at $37^{\circ} \mathrm{C}$. for 96 hours showed no increase in homocitrulline or diminution in lysine, a finding that had been confirmed by T. Gerritsen (1962, personal communication) on sterile urine to which urea and lysine had been added.

1 - and 3-methyl histidines were observed only in the adult urines except for small amounts in one of the full-term infants; these amino acids have not previously been reported in the urine under 5 months of age (Scriver, 1960). Taurine, which is not an amino acid is efficiently reabsorbed at all stages of maturity despite the higher plasma levels in the infants.

\section{Summary}

The plasma levels and urinary excretion rates of 


\begin{tabular}{|c|c|c|c|c|c|c|c|c|c|c|}
\hline \multirow{2}{*}{$\frac{\text { Term } 1}{T R}$} & \multicolumn{2}{|c|}{ Full Term 2} & \multicolumn{2}{|c|}{ Full Term 3} & \multicolumn{2}{|c|}{ Adult 1} & \multicolumn{2}{|c|}{ Adult 2} & \multicolumn{2}{|c|}{ Adult 3} \\
\hline & $\mathrm{C}_{\mathrm{a} a}$ & TR & $\mathrm{C}_{\mathrm{a} a \mathrm{i}}$ & TR & $\mathrm{C}_{\mathrm{aa}}$ & TR & $\mathrm{C}_{\mathrm{aa}}$ & TR & $\mathrm{C}_{\mathrm{aa}}$ & TR \\
\hline 95 & $0 \cdot 12$ & 99 & $1 \cdot 2$ & 98 & $6 \cdot 8$ & 93 & 28 & 72 & $7 \cdot 0$ & 94 \\
\hline $\begin{array}{l}(1) \\
(2)\end{array}$ & $\overline{9 \cdot 4}$ & $\begin{array}{l}(1) \\
82\end{array}$ & 16 & $\begin{array}{l}(1) \\
73\end{array}$ & $14 \overline{2}$ & $\overline{86}$ & $9 \overline{9 \cdot 0}$ & $\overline{87}$ & $\overline{3 \cdot 5}$ & $\overline{97}$ \\
\hline 92 & $\begin{array}{l}9 \cdot 4 \\
3 \cdot 8\end{array}$ & $\begin{array}{l}82 \\
93\end{array}$ & $\begin{array}{r}10 \\
5.9\end{array}$ & 90 & $\begin{array}{r}14 \cdot 2 \\
0.91\end{array}$ & $\begin{array}{l}86 \\
99\end{array}$ & $\begin{array}{l}9.0 \\
0.73\end{array}$ & $\begin{array}{l}81 \\
99\end{array}$ & $\begin{array}{l}3 \cdot 5 \\
0 \cdot 38\end{array}$ & $\begin{array}{l}91 \\
99\end{array}$ \\
\hline 85 & $6 \cdot 6$ & 87 & $9 \cdot 6$ & 84 & $3 \cdot 1$ & 97 & $2 \cdot 4$ & 98 & $1 \cdot 0$ & 99 \\
\hline 96 & $3 \cdot 1$ & 94 & $3 \cdot 6$ & 94 & 0.95 & 99 & 0.93 & 99 & 0.43 & 99 \\
\hline 86 & $2 \cdot 7$ & 95 & $1 \cdot 7$ & 97 & - & (2) & - & (2) & - & (2) \\
\hline 99 & $3 \cdot 0$ & 94 & $2 \cdot 2$ & 96 & $0 \cdot \overline{28}$ & 99 & 0.09 & 99 & $\overline{0.04}$ & 99 \\
\hline 96 & - & - & - & (2) & - & (2) & - & (2) & - & (2) \\
\hline 45 & 21 & 59 & 22 & 64 & 55 & 94 & $4 \cdot 3$ & $96^{\prime}$ & $1 \cdot 8$ & 98 \\
\hline 95 & $2 \cdot 4$ & 95 & $2 \cdot 9$ & 95 & 0.55 & 99 & 0.72 & 99 & $0 \cdot 25$ & 99 \\
\hline (1) & - & (1) & - & (1) & $2 \cdot 3$ & 98 & $1 \cdot 4$ & 99 & 0.82 & 99 \\
\hline (1) & - & (.) & - & (1) & - & (1) & - & (1) & - & (1) \\
\hline $99^{\prime}$ & 0.50 & $99^{\prime}$ & $0 \cdot 32$ & $99^{\prime}$ & $0 \cdot 18$ & 99 & 0.15 & 99 & 0.02 & 99 \\
\hline (1) & - & (1) & $2 \cdot 5$ & 96 & 0.93 & 99 & 0.74 & 99 & $0 \cdot 27$ & 99 \\
\hline (1) & - & (1) & - & (1) & - & (1) & - & (1) & - & (1) \\
\hline $\begin{array}{l}(1) \\
97\end{array}$ & $\overline{4 \cdot 3}$ & $\begin{array}{l}(1) \\
91\end{array}$ & $2 \overline{\cdot 9}$ & $\begin{array}{l}(1) \\
95\end{array}$ & $\overline{1 \cdot 7}$ & $\begin{array}{l}\text { (1) } \\
98\end{array}$ & $\overline{1 \cdot 0}$ & $\begin{array}{l}\text { (1) } \\
99\end{array}$ & $\overline{1.9}$ & (1) \\
\hline 99 & $1 \cdot 7$ & 97 & $1 \cdot 3$ & 98 & 0.40 & $\begin{array}{l}70 \\
99\end{array}$ & 0.51 & 99 & $\begin{array}{l}1.9 \\
0 \cdot 14\end{array}$ & $\begin{array}{l}98 \\
99\end{array}$ \\
\hline 99 & $1 \cdot 2$ & 98 & $0 \cdot 78$ & 99 & 0.31 & 99 & $0 \cdot 34$ & 99 & $0 \cdot 13$ & 99 \\
\hline 98 & 1.9 & 96 & $1 \cdot 7$ & 97 & 1.8 & 98 & $1 \cdot 5$ & 99 & 1.9 & 98 \\
\hline 99 & $1 \cdot 9$ & 96 & - & - & $1 \cdot 0$ & 99 & $1 \cdot 0$ & 99 & $1 \cdot 0$ & 99 \\
\hline- & - & - & - & - & - & - & - & - & - & - \\
\hline (1) & - & (1) & - & (1) & - & (1) & - & (1) & - & (1) \\
\hline (1) & - & (1) & - & (1) & - & (1) & - & - & - & - \\
\hline$\overline{99}$ & $\overline{1 \cdot 1}$ & $\overline{98}$ & $\overline{0.63}$ & $\overline{99}$ & - & $\overline{(2)}$ & - & $\overline{(2)}$ & - & $\overline{(2)}$ \\
\hline (1) & 1 & - & - & - & - & (1) & - & (1) & - & (1) \\
\hline 64 & 16 & 69 & 21 & 65 & $8 \cdot 3$ & 92 & $4 \cdot 3$ & 96 & $2 \cdot 2$ & 98 \\
\hline (1) & - & - & - & - & - & (1) & - & (1) & - & (I) \\
\hline $99^{\prime}$ & $1 \cdot 0$ & 98 & - & (2) & - & (2) & - & (2) & - & (2) \\
\hline 95 & $6 \cdot 3$ & 88 & $2 \cdot 3$ & $96^{\prime}$ & $1 \cdot 2$ & 99 & 0.64 & 99 & $0 \cdot 13$ & 99 \\
\hline
\end{tabular}

$\mathrm{C}_{\mathrm{aa}}=$ renal amino acid clearance $=U \mathrm{UV} / \mathrm{P}_{\mathrm{aa}} \mathrm{ml} . / \mathrm{min} . / 1 \cdot 73 \mathrm{~m}^{2} .(5)$.

$\mathrm{TR}=$ per cent. renal tubular reabsorption of amino acids $=100\left(1-\mathrm{UV} / \mathrm{P}_{\mathrm{aa}} \cdot 1 / \mathrm{Cer}_{\mathrm{er}}\right)$.

32 amino acids and related compounds have been measured in four fasting premature infants and three full-term infants. The values for renal clearance and renal tubular reabsorption have been calculated for 21 of these and compared to the figures for three adults.

The main patterns of renal tubular conservation of amino acids have been discussed in relation to pre-renal factors, to known common reabsorptive pathways and to structural relations.

The authors would like to thank Dr. Charles Scriver for his help in preparing the tevt. This study was supported by USPHS grants A-1066 and FR-69-01.

\section{REFERENCES}

Barnett, H. L. and Vesterdal, J. (1953). The physiologic and clinical significance of immaturity of kidney function in young infants. J Pediat , 42, 99.

Childs, B. (1952). Urinary excretion of free alpha-amino acid nitrogen by normal infants and children. Proc. Soc. exp. Biol (N.Y) 81,225 .

Cusworth, D. C. and Dent, C. E. (1960). Renal clearances of amino acids in normal adults and in patients with aminoaciduria. Biochem. J., 74, 550 .

Doolan, P. D., Harper, H. A., Hutchin, M. E. and Alpen, E. L. (1956). The renal tubular response to amino acid loading. $J$. clin. Invest., 35, 888 .

- and Shreeve, W. W. (1955), Renal clearance of eighteen individual amino acids in human subjects. ibid., 34, 1247.
Dustin, J. P., Moore, S. and Bigwood, E. J. (1955). Chromatographic studies on the excretion of amino acids in early infancy. Metabolism 4, 75 .

Evered, D. F. (1956). The excretion of amino acids by the human. A quantitative study with ion-exchange chromatography.

Fowler, D. I., Norton, P. M., Cheung, M. W. and Pratt, E. L. (1957). Observations on the urinary amino acid excretion in man; the influence of age and diet. Arch. Biochem., 68, 452.

Gerritsen, T., Lipton, S. H., Strong, F. M. and Waisman, H. A. (1961) On the isolation and identification of homocitrulline from urine. Biochem. biophys. Res. Commun., 4, 379.

Hepner, R. and Lubchenco, L. O. (1960). A method for continuous urine and stool collection in young infants. Pediairics, 26, 828

Jagenburg, O. R. (1959). The urinary excretion of free amino acids and other amino compounds by the human. Scand. J. clin. Lab. Invest., 11 , supp!. 43.

McCance, R. A., Naylor, N. J. B. and Widdowson, E. M. (1954). The response of infants to a large dose of water. Arch. Dis. Childh., 29, 104.

Neame, K. D. (1961). Phenylalanine as inhibitor of transport of amino-acids in brain. Nature (Lond.), 192, 173.

O'Brien, D. Bergstedt, J. Butterfield, J., Ibbott, F and Lubchenco, L. (1960). Observations on the urinary excretion of free amino acids by the premature infant. Acta paediat. (Uppsala), 49, 258.

Owen, J. A., Iggo, B., Scandret t, J. and Stewart, C. P. (1954). The determination of creatinine in plasma or serum, and in urine; a critical examination. Biochen. J., 58, 426.

Robson, E. B. and Rose, G. A. (1957). The effect of intravenous lysine on the renal clearances of cystine, arginine and ornithine in normal subjects, in patients with cystinuria and Fanconi syndrome and in their relatives Clin $S c i$, 16,75 .

Scriver, C. R. (1960). Vitamin $B_{6}$-dependency and infantile convulsions. Pediatrics, 26, 62

(1962). Hereditary aminoaciduria. In Progress in Medical Genetics, Vol. 2, p. 83. Grune and Stratton, New York.

, Schafer, I. A. and Efron M. L. (1961). New renal tubular amino-acid transport system and new hereditary disorder of amino-acid metabolism. Nature (Lond.), 192, 672.

Sereni, F., McNamara, H., Shibuya, M., Kretchmer, N. and Barnett H. L. (1955). Concentration in plasma and rate of urinary excretion of amino acids in premature infants. Pediatrics, 15, 575 . 
Spackman, D. H., Stein, W. H. and Moore, S. (1958). Automatic recording apparatus for use in the chromatography of amino acids. Analyt. Chem., 30, 1190.

Stark, G. R., Stein, W. H. and Moore, S. (1960). Reactions of the cyanate present in aqueous urea with amino acids and proteins. J. biol. Chem., 235, 3177.
Stein, W. H. and Moore, S. (1954). The free amino acids of human blood plasma. ibid., 211,915 .

Webber, W. A. (1962). Interactions of neutral and acidic amino acids in renal tubular transport. Amer. J. Physiol., 202, 577 acids in renal tubular transport. Amer. J. Physiol., 202, 577 . acids in renal tubular transport. ibid., 200, 380 .

Woolf, L. I. and Norman, A. P. (1957). The urinary excretion of amino acids and sugars in early infancy. J. Pediat., 50, 271. 